\title{
ANÁLISIS DE LA EVOLUCIÓN HISTÓRICA DE LA ESTRUCTURA ECONÓMICA DE LAS FUERZAS ARMADAS REVOLUCIONARIAS DE COLOMBIA (FARC) COMO FACTOR PRINCIPAL DE LA PERPETUACIÓN DEL CONFLICTO ARMADO COLOMBIANO
}

Analysis of historical evolution of the economic structure of las Fuerzas Armadas Revolucionarias de

Colombia (FARC) as main factor of the Colombian armed conflict perpetuation

\author{
Mayra Alejandra Lozano Rodríguez ${ }^{1}$, David González CuencA ${ }^{2}$ \\ Universidad Santo Tomás, Bogotá, Colombia ${ }^{1}$ \\ Universidad Militar Nueva Granada, Bogotá, Colombia ${ }^{2}$
}

KEY WORDS

Armed Conflict

Colombian Conflict

Economic Theories

Drug Trafficking
ABSTRACT

In this article, a historical compilation of the economic structure of the Revolutionary Armed Forces of Colombia (FARC) was carried out, in which the intentions of its origin, its behavior in the period from 1966 to 2013, are analyzed, based on some theories Explanations; And finally the interference of this structure in the perpetuation of the conflict in the Colombian State is determined. For this purpose we used qualitative and quantitative information found in different academic articles.
PALABRAS CLAVE

Conflicto Armado Conflicto colombiano Teorías Económicas Narcotráfico
RESUMEN

En este artículo se realizó una recopilación histórica de la estructura económica de las Fuerzas Armadas Revolucionarias de Colombia -FARC-, en la cual se analizan las intenciones de su origen, su comportamiento en el periodo comprendido entre 1966 y 2013, con base en algunas teorías económicas que permiten explicarlo; y finalmente se determina la injerencia de dicha estructura en la perpetuación del conflicto armado en el Estado colombiano. Para tal fin se utilizó información cualitativa y cuantitativa encontrada de diferentes fuentes académicas. 


\section{Introducción}

$\mathrm{C}$ olombia ha estado sumida en un conflicto armado con diferentes grupos insurgentes, entre los cuales se encuentra las Fuerzas Armadas Revolucionarias de ColombiaFARC, con quienes se firmó un acuerdo de paz en el año 2016. Dicho grupo inició como un movimiento campesino, que posteriormente fue denominado por el Estado y diferentes actores internacionales como "guerrilla", "narco guerrilla", "terrorista" y "narcoterroristas"; un apelativo directamente relacionado con sus acciones militares y sus actividades económicas ilegales.

Es claro que quien practica la guerra debe poseer los recursos para sostenerla, y las FARC no han sido la excepción; lograron desarrollar una estructura económica que le permitió sustentar sus tropas y mantener firme sus intenciones bélicas. Es por ello, que éste ha sido un tema prioritario en la agenda de las investigaciones de los economistas nacionales, teniendo en cuenta que el conflicto colombiano y sus implicaciones políticas afectan a gran parte de las variables económicas, como el producto interno bruto, el bienestar social, la inversión privada, el gasto público y el consumo de las familias (Valencia, 2006, p. 142).

De la misma manera, se afirma que las guerras han influido decisivamente en la economía, sus actores y sus procesos, y con frecuencia los conflictos bélicos, incluso, han determinado los patrones del comercio internacional y la creación de instituciones y organismos internacionales (Langa, 2011. p. 15); En este sentido, Mokyr (2003) ratifica la influencia de los conflictos bélicos sobre el funcionamiento de las actividades comerciales, del mercado del trabajo y la disponibilidad de los recursos (Citado por Langa 2011, p. 90).

Teniendo en cuenta lo anterior, este documento busca identificar las intenciones económicas de las FARC durante su origen, analizar el comportamiento de la estructura económica de las FARC en el periodo comprendido entre 1966 y 2013, y finalmente determinar la injerencia de la estructura económica de este grupo en la perpetuación del conflicto con el Estado colombiano. Para tal fin se utilizará información cualitativa encontrada en diferentes artículos académicos y noticias del tema.

El periodo tomado para este análisis, se subdivide en tres grupos: el primero entre los años 1965 y 1978, el segundo entre 1979 y 1990, y el tercero entre 1991 y 2013. Adicionalmente, cada periodo es correlacionado con algunas teorías, que son de utilidad para explicar el comportamiento económico que tuvo las FARC durante el periodo analizado, los cuales se describen a continuación:
- De 1965 a 1978, podemos entender que el comportamiento de la actividad económica de las FARC se fundamentaba teóricamente en aspectos económicos clásicos: El Feudalismo y la Fisiocracia, como fundamento para el desarrollo económico y un ideal de mejoramiento de la calidad de vida de los campesinos, basado en la agricultura Rio (2010). Concibe el feudalismo como un sistema económico de producción basado en la agricultura y la ganadería, en el cual cada feudo debía producir lo que era necesario para su sostenimiento y en consecuencia, existía una diferenciación social entre los señores de las tierras y los campesinos (p. 191). Así mismo se destaca la fisiocracia en la medida que se entiende la agricultura como la fuente de excedentes o riquezas, donde los arrendatarios y trabajadores agrícolas desempeñan un papel fundamental en la sociedad (Ferrer, 2003, p.220).

- De 1979 a 1990, la apertura económica mundial, las nuevas interacciones comerciales y las nuevas redes internacionales provenientes del comercio nos llevan a entender El Neoliberlismo - Para justificar teóricamente su incursión en el Narcotráfico, excluyendo al Estado como ente regulador y su fortalecimiento en las zonas donde el mismo no estaba presente.

El Neoliberalismo pretende aumentar el poder del mercado a expensas del debilitamiento del Estado, es decir una función mínima que comprendía su exclusión en la producción de bienes básicos relacionados con la estructura económica; la consolidación como un Estado Social que implementara un sistema de protección en el que la dinámica del mercado es coherente con el concepto de justicia social: que se abstuviera de dirigir la inversión productiva, y el desarrollo tecnológico y científico; y por último, que dejara de regular los mercados con el fin de que estos se autorregularan (Bresser, 2009:85-86).

- De 1991 a 2013, se identifica la la Teoría Económica de los Bienes Ilegales- Para justificar su estructuración como una organización autónoma, tecnológica, que se va consolidando y creciendo en la medida en que el Estado ejerce presión.

En el avance para la creación de una teoría económica de los bienes ilegales, Ortiz (2001) propuso un modelo en el que se prueba que la represión por parte el Estado al narcotráfico, induce un precio de equilibrio superior al que se fijaría sin reprensión; y que el efecto de cambios en la probabilidad de prohibición de la oferta de estupefacientes depende de la elasticidad del precio de la demanda. Más adelante Ortíz (2003) realiza 
algunas predicciones adicionales a este análisis: afirma que "para la economía cerrada como para el modelo con comercio internacional, se prueba que un aumento en la probabilidad de interdicción $y$ destrucción de las drogas, conduce a un aumento de las actividades ilícitas $y$, en particular, a un incremento en la proporción de la mano de obra que se emplea en el sector productor de estupefacientes"; lo que implica que las políticas de reprensión a la oferta son contraproducentes. (Citado por Raffo, 2011:295).

Adicionalmente, en el 2009 Ortíz hace otro aporte a la teoría de bienes ilegales al investigar las reacciones de los narcotraficantes ante las políticas de erradicación e interdicción aplicadas por el gobierno, encontrando que se ha generado un cambio tecnológico en las actividades ilegales que ha logrado compensar el impacto de las acciones de reprensión al mercado, lo cual ha permitido que los precios no suban, favoreciendo dicha actividad (Raffo, 2011:300).

Luego de establecer las características que las diferentes teorías económicas aportan para correlacionarlas con el funcionamiento histórico del desarrollo económico de las FARC, se prosigue con la dilucidación de las actividades económicas de esta guerrilla que ligadas a un periodo de tiempo determinado generan una definición casi ideológica de su comportamiento económico.

\section{Estructura económica de las FARC}

\section{Por una reforma agraria - 1965 a 1977:}

Para establecer cuál fue la idea principal de las FARC, en términos económicos, al conformarse como un grupo guerrillero es necesario partir del contexto histórico de la época. En primera instancia el conflicto armado colombiano se da en el periodo conocido como "La violencia", en el cual se desarrolló una guerra civil que tuvo lugar entre 1946 y 1966, entre liberales y conservadores, (Yaffe, 2011, p. 191). Es de mencionar que para este periodo se concebía un desarrollo económico basado en la agricultura, de donde provenían las riquezas del Estado; sin embargo al igual que los fisiócratas ${ }^{1}$ (Domínguez, 2004, pp. 2-3), los campesinos consideraban que la explotación agrícola debía hacerse bajo un régimen de libertad, es decir sin la intervención directa del Estado, ya

\footnotetext{
${ }^{1}$ La fisiocracia es una teoría económica formulada en la segunda mitad del siglo XVIII, por François Quesnay, en oposición a las políticas restrictivas del mercantilismo de la época. Para los fisiócratas la principal fuente de riqueza provenía de la agricultura, y consideraban que el comercio de sus productos debía hacerse libremente, teniendo en cuenta que los campesinos eran quienes trabajaban la tierra, y que el Estado era benefactor de la utilidad de esta actividad.
}

que su injerencia privilegiaba principalmente a las clases altas.

Frente al análisis que se puede desarrollar sobre las causas primarias del surgimiento de las FARC se identifican las dificultades que desde los años 30 empezaron a padecer por la implementación de leyes enfocadas a la productividad de la tierra y la redistribución de la tenencia. El dominio y la concentración de las propiedades en el sector rural se evidenciaron como un problema que el Estado debía atacar, específicamente la extinción de dominios de terrenos baldíos, la legalización de posesión de parcelas por parte de arrendatarios y la legalización de títulos de aquellos terrenos con dominio incierto o dificultades jurídicas. (Franco \& Ríos, 20111, pág. 102)

Por otro lado, teniendo en cuenta el contexto internacional de la época en el cual se empezaban a generar movimientos de izquierda inspirados en la revolución cubana, Washington decide ejecutar el plan LASSO (Latin American Security Operation) para financiar la ejecución de operaciones militares con el fin de acabar con estas agrupaciones insurgentes. Para entonces, aunque el partido comunista estaba presente en Colombia, era marginal, ya que su participación se limitaba a la lucha agraria y la generación de colonias campesinas. En consecuencia, el Ejército Nacional de Colombia emprende la operación "Marquetalia" refiriéndose al ataque en contra de campesinos comunistas que se habían organizado como grupos de autodefensa (Salazar, 2005, p. 123) con la intención de establecer el orden y fomentar el mejoramiento de la calidad de vida de los campesinos a través de la agricultura. El ejército nacional entró en la región disparando y bombardeando indiscriminadamente, e incluso se dispersaron virus y bacterias en frascos de vidrio, que posteriormente produjeron enfermedades cutáneas (Sánchez, 2013, p. 49).

Es de resaltar, que algunos de los grupos de autodefensa conformados en esa región estaban liderados por Manuel Marulanda Vélez y Jacobo Arenas, quienes posteriormente, en respuesta al ataque del ejército, fundarían las FARC en 1964 y la oficializarían en mayo de 1966 en la Segunda Conferencia de las Guerrillas del Bloque Sur (Sánchez, 2013, p. 161). Su ideal estaba alineando a la teoría marxista ${ }^{2}$, que pretendía expropiar al capitalista de la explotación de los obreros, en el

\footnotetext{
2 Para Marx, el productor y los dueños de los medios de producción son la misma persona, lo cual establece a la propiedad como un factor relevante en las relaciones sociales de producción. Marx propone una estructura económica basada en clases sociales, al evidenciar que la retribución que recibía el obrero era menor al tiempo de producción que este invertía en su trabajo, desposeyéndolo así de los medios de producción.
} 
marco de la lucha de las clases sociales (Valdés, 2013. p. 68); en este sentido considerando la tierra como fuente eficaz del desarrollo económico, las FARC apropiaron un discurso de lucha por una repartición más justa de las riquezas, priorizando a los campesinos pobres.

Con la creación del Instituto Colombiano de Reforma Agraria - INCORA, en el año 1966 bajo los criterios de dotación de tierras productivas a los campesinos, establecimiento productivo de las tierras y provisión de servicios básicos en los terrenos, se da una explosión de creación de instituciones dedicadas a la protección y coordinación de varios sectores productivos nacionales. Nuevamente se instituyeron leyes para fomentar la redistribución de las tierras y el aprovechamiento de aquellas que fueran baldías o improductivas. Aparentemente todo ello obedeciendo a las dificultades manifiestas de los campesinos quienes cada día comulgaban más con los planteamientos revolucionarios de la recién creada guerrilla de las FARC. (Franco \& Ríos, 2011).

En primer lugar, se trataba más bien de una guerrilla presente en zonas social y geográficamente marginales, y que sólo atacaba si era sorprendida por el ejército (Sánchez, 2013, p. 86); no eran muy fuertes debido a la falta de organización militar, la superioridad en número del ejército y la falta de recursos financieros (Salazar, 2005, p. 124). Su actividad económica durante este periodo se basaba principalmente en la caza, y el cultivo de yuca, plátano, y caña de azúcar, ya que contaban con sus propias plantaciones; adicionalmente se sostenían con recursos provenientes del saqueo de almacenes, robos a la Caja Agraria, y contribuciones forzosas a los hacendados y secuestrados (Sánchez, 2013, p. 84), tal como se evidencia en la siguiente tabla:

Tabla No. 1. Secuestros de las FARC entre 1970 y 1978.

Teniendo en cuenta lo anterior, se evidencia el origen del conflicto armado en el resentimiento y la desigualdad (Yaffe, 2011, p. 94), y un interés profundo de las FARC en el establecimiento del orden y la defensa de los "pobres", especialmente en los lugares donde el Estado no estaba presente, y donde el control lo ejercían los hacendados, quienes eran campesinos adinerados que abusaban de los trabajadores que tenían a su cargo.

De esta manera establece la propiedad privada como fruto del trabajador individual e independiente que con sus instrumentos y medios de trabajo la podían adquirir; este postulado pretendía expropiar al capitalista de la explotación de los obreros, en el marco de la lucha de las clases sociales.
Tabla No. 1. Secuestros de las FARC entre 1970 y 1978.

\begin{tabular}{|c|c|c|c|c|c|}
\hline Año & Frente & Municipio & Departamento & Ocupación & Valor Rescate \\
\hline 1970 & & & Huila & Hacendado & $\$ 150.000$ \\
\hline 1975 & & Tacueyó & Cauca & $\begin{array}{l}\text { Cónsul } \\
\text { Holandés }\end{array}$ & \\
\hline 1975 & & Cimitarra & Santander & Hacendado & $\$ 3.000 .000$ \\
\hline 1975 & & $\begin{array}{l}\text { Puerto } \\
\text { Olaya }\end{array}$ & Antioquia & Hacendado & $\$ 4.000 .000$ \\
\hline 1975 & $\begin{array}{l}\text { Ricardo } \\
\text { Franco }\end{array}$ & Cimitarra & Santander & Hacendado & $\$ 1.000 .000$ \\
\hline 1976 & & Remedios & Antioquia & Industrial & $\$ 30.000 .000$ \\
\hline 1976 & $\begin{array}{l}\text { Aguas } \\
\text { Calientes }\end{array}$ & & & Industrial & $\$ 1.000 .000$ \\
\hline 1977 & & & $\begin{array}{l}\text { Santander- } \\
\text { Antioquia }\end{array}$ & Hacendado & $\$ 10.000 .000$ \\
\hline 1977 & & $\begin{array}{l}\text { Puerto } \\
\text { Berrio }\end{array}$ & Antioquia & Hacendado & $\$ 10.000 .000$ \\
\hline 1977 & & Neiva & Huila & Médico & $\$ 5.000 .000$ \\
\hline 1977 & & Neiva & Huila & Ganaderos & \\
\hline 1977 & & & Huila & Estudiante & $\$ 3.000 .000$ \\
\hline 1977 & & Chigorodó & Antioquia & $\begin{array}{l}\text { Industrial } \\
\text { Alemán }\end{array}$ & \\
\hline 1977 & Sexto & Santa Rosa & Cauca & $\begin{array}{l}\text { Maestra de } \\
\text { Escuela }\end{array}$ & \\
\hline 1978 & & & $\begin{array}{l}\text { Santander- } \\
\text { Antioquia }\end{array}$ & Hacendado & \\
\hline 1978 & Cuatro & Cimitarra & Santander & Ganadero & $\$ 2.000 .000$ \\
\hline 1978 & & & & $\begin{array}{l}\text { Geólogo } \\
\text { E.E.U.U }\end{array}$ & \\
\hline 1978 & & & & Industriales & \\
\hline 1978 & & Montañita & Caquetá & Ganadero & \\
\hline 1978 & & Montañita & Caquetá & $\begin{array}{l}\text { Inspector de } \\
\text { Policía }\end{array}$ & \\
\hline
\end{tabular}

Fuente: Sánchez (2013), Guerrilla y Población Civil: Trayectoria de las FARC 1949-2013, Centro de Memoria Histórica (p. 85), Bogotá- Colombia.

\section{Fortalecimiento económico de las FARC - 1979 a 1990:}

En un segundo periodo comprendido entre 1979 y 1990, se hace evidente el inicio de su participación y consolidación en el negocio de la coca, el cual estaba directamente relacionado con la intencionalidad de expandirse, según lo manifestado en su VI Conferencia realizada en 1978, donde también se socializó su determinación de dejar de ser un grupo pasivo y secundario, bajo una modalidad denominada "nuevo modo de operar" que consistía en buscar al enemigo y atacarlo (Sánchez, 2013, pp. 105-109). Se afirma que precisamente en este año las FARC decidieron actuar en las regiones dedicadas a los cultivos de coca (Gutiérrez y Barón, 2008, p. 120), lo que les permitió empezar a canalizar los recursos provenientes de la misma para fortalecer su actividad bélica.

Durante este tiempo la incursión en las zonas donde se difundía aceleradamente estos cultivos y que se caracterizaban por la escaza presencia estatal, se empezó a identificar diferentes frentes, que además de estar allí por la extracción de recursos, buscaban apoyo social mediante la oferta de protección a los campesinos que se encontraban en manos de comerciantes y bandas criminales que se dedicaban al Narcotráfico. A menudo estas zonas eran muy afectadas por la violencia y la superproducción de droga que causaba una fuerte caída en los precios (Sánchez, 2013, pp. 142-156); 
Análisis de la evolución histórica de la estructura económica de las Fuerzas Armadas Revolucionarias de Colombia (FARC) como factor principal de la perpetuación del conflicto armado colombiano

en lo cual la guerrilla tuvo una importante participación, tanto para reducir los niveles de violencia, como para regular los precios. Las FARC obligaban a los campesinos a cultivar dos hectáreas de pancoger ${ }^{3}$ por cada hectárea de cultivos ilícitos y que fijaban los precios de compra a los intermediarios (Gutiérrez y Barón 2008, p. 120).

Los recursos provenientes de la coca consistían principalmente en la imposición del impuesto de "gramaje" 4 a los cultivadores, el cual oscilaba entre un $10 \%$ y $15 \%$ sobre el valor total de la transacción; el cobro a los narcotraficantes por la vigilancia de sus laboratorios y por la asistencia brindada en el momento del despegue de los aviones cargados con droga. Así mismo se identifican recursos provenientes del secuestro, la vacuna ganadera, que consistía en un impuesto por cada cabeza de ganado, los impuestos por producción de oro, las extorsiones a palmicultores y los asaltos (Sánchez, 2013, p.146).

Esta relación dada entre las FARC y el narcotráfico está ligada al pensamiento económico neoliberalista, que "pretende aumentar el poder del mercado a expensas del debilitamiento del Estado, es decir una función mínima que comprendía su exclusión en la producción de bienes básicos relacionados con la estructura económica; la consolidación como un Estado social que implementará un sistema de protección en el que la dinámica del mercado es coherente con el concepto de justicia social: que se abstuviera de dirigir la inversión productiva, y el desarrollo tecnológico y científico; y por último, que dejara de regular los mercados con el fin de que estos se autorregularan". (Bresser, 2009, pp. 85-86). Es así como las FARC incursionan en el narcotráfico como ente regulador del mercado de la coca, fortaleciéndose en las zonas marginales donde hacían falta obras infraestructurales y servicios públicos.

Varios autores describen que los incentivos del narcotráfico son la principal fuente de financiación de este grupo guerrillero. Al respecto Gutiérrez y Barón (2008), identifica que a mediados de los años 80 Colombia se transformó en el principal productor y exportador de cocaína, generando una enorme riqueza ilegal que financió a guerrilleros, paramilitares y funcionarios del Estado (p.116), atribuyéndole así la denominación a estos grupos como narco-guerrillas. Dicho calificativo fue utilizado como un instrumento de deslegitimación de la "lucha por el pueblo", que había sido proclamada en la VII Conferencia de las FARC, realizada en 1982 .

\footnotetext{
${ }^{3}$ Los productos de pancoger son cultivos que satisfacen parte de las necesidades alimenticias de una población determinada.

${ }^{4}$ Se refiere a un impuesto proporcional a la cantidad de droga producida y comercializada.
}

Es en esta Conferencia donde deciden adquirir el nombre EP - Ejército del Pueblo, y se identifica la cordillera Oriental como eje fundamental de su estrategia de despliegue, ubicando doce frentes guerrilleros y ocho bloques adicionales, que permitieron concretar un número total de cuarenta $\mathrm{y}$ ocho frentes en todo el territorio colombiano a cargo de veintiocho mil hombres. (Bottía, 2003, pág. 2)

En el mismo ámbito, otros de los ingresos más significativos para las FARC durante este periodo provienen del secuestro. En consecuencia, el presidente Belisario Betancur impulsa en 1984 una negociación mediante el acuerdo denominado "La Uribe" en el cual se establece un cese al fuego y la abolición de la práctica del secuestro a cambio del impulso, por parte del gobierno, de reformas políticas, económicas y sociales. Producto de esta negociación se conformó la Unión Patriótica, un partido político en oposición a los movimientos tradicionales, de apertura democrática, y coherente con las propuestas de las FARC (Sánchez, 2013, pp. 124-149); aún así la guerrilla no dejó de secuestrar, tal como se evidencia en el gráfico No. 1.

Gráfico No. 1. Secuestros de las guerrillas y el paramilitarismo entre 1979-1990.

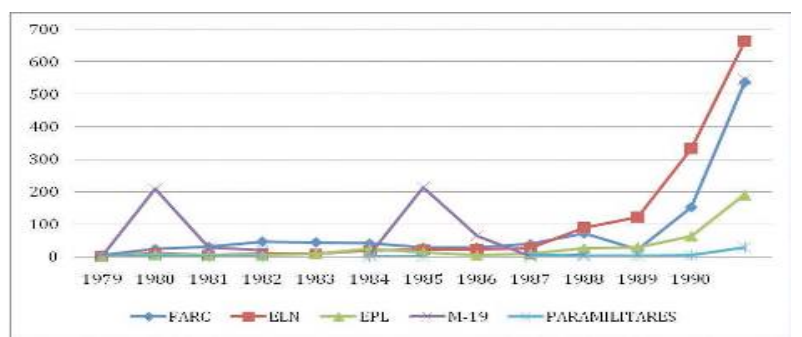

Fuente: Sánchez (2013), Guerrilla y Población Civil: Trayectoria de las FARC 1949-2013, Centro de Memoria Histórica, Bogotá- Colombia.

Ahora bien, al retomar el tema del narcotráfico como actividad principal de las FARC, es de mencionar que en la Conferencia Drug Trafficking and the Peace Process in Colombia, realizada el 13 de Mayo de 2014 por Wilson Center, Latin American Program, FIP y NOREF, se refirió que en un principio la alianza narcotráticantes- FARC fue beneficiosa principalmente para los capos, donde las partes salían favorecidas. Pero la ambición del dinero indujo a la organización guerrillera a robarle a los mafiosos droga, dinero y armas, situación que generó un fuerte enfrentamiento que finalmente condujo al grupo subversivo a dar el salto para involucrarse de lleno en el negocio de las drogas ilícitas, tal como lo vemos en los siguientes años analizados. 


\section{El detrimento de las FARC- 1991 a 2013:}

El comportamiento económico de las FARC para un tercer periodo, comprendido entre 1991 y 2013, contó con una evidente participación de la guerrilla en el narcotráfico. Según las cifras dadas por la Consejería para la Defensa y Seguridad Nacional, el promedio anual de los ingresos de las FARC procedentes de la droga, representaba un $50 \%$ en el año 2013; para esta época ya poseían sus propias siembras y laboratorios, e incluso se asume que eran socios en envíos de drogas al exterior (Sánchez, 2013, p. 193) vinculados al cartel de Medellín y narcotraficantes reconocidos como el brasileño Fernandinho Beira-Mar; así mismo, en los años 90 este grupo estaba participando en masivos embarques de cocaína a Estados Unidos y otros mercados, y también estaba proveyendo protección de algunas rutas, o al menos, de segmentos de ellas (Gutiérrez y Barón 2008, p. 120). De esta manera, se atribuye en promedio unos 500 y 800 millones de dólares de ingresos provenientes del narcotráfico (Sánchez, 2013, p. 194).

En consecuencia, ante el incremento de control y participación de las FARC en este mercado ilícito, el Estado, bajo la presidencia de Andrés Pastrana ejecuta el denominado Plan Colombia, en el cual las FARC empezaron a mostrar ciertas debilidades referentes a la falta de capacidad para responder a los ataques aéreos de la fuerza pública, movilizar rápidamente sus tropas, y la incapacidad de lograr convertir su guerra en un ejercicio popular; lo que los llevo a optar nuevamente por los diálogos de paz en la llamada "zona de despeje".

Teniendo en cuenta lo anterior, se puede observar que entre 1991 y 2001 las FARC tuvieron un gran auge económico pese a las medidas tomadas por el Estado a través del Plan Colombia; dicho posicionamiento económico puede correlacionarse con la teoría económica de los bienes ilegales ${ }^{5}$ en la cual Ortiz (2001) propone un modelo en el que se prueba que la represión por parte el Estado al narcotráfico, induce un precio de equilibrio superior al que se fijaría sin reprensión; y que el efecto de cambios en la probabilidad de prohibición de la oferta de estupefacientes depende

${ }^{5}$ La teoría económica de los bienes ilegales nace en el marco de una investigación realizada por Jeffrey Miron que buscaba establecer los efectos de la prohibición de las drogas sobre sus precios en los mercados negros de la cocaína y la heroína; allí se compara el efecto de un impuesto en un contexto legal sobre los precios de la droga y la producción en un contexto ilegal, con el fin de darle respuesta a la pregunta de investigación“ ¿Por qué a lo largo de los últimos 25 años los precios reales de la cocaína ajustados por niveles de pureza han bajado dramáticamente, mientras buena parte de las medidas de control han aumentado y la producción y el consumo de drogas duras apenas ha crecido?". En consecuencia se evidencia que los precios de la droga en el mercado negro, son más altos que en el mercado legal (Raffo, 2011:294). de la elasticidad del precio de la demanda. Más adelante Ortíz (2003) realiza algunas predicciones adicionales a este análisis: afirma que

Para la economía cerrada como para el modelo con comercio internacional, se prueba que un aumento en la probabilidad de interdicción y destrucción de las drogas, conduce a un aumento de las actividades ilícitas y, en particular, a un incremento en la proporción de la mano de obra que se emplea en el sector productor de estupefacientes; lo que implica que las políticas de reprensión a la oferta son contraproducentes (Citado por Raffo, 2011, p. 295).

Adicionalmente, la creación o adquisición de laboratorios de las FARC y su participación en el envío de droga al exterior se puede justificar con esta teoría en relación al aporte dado en el 2009 por Ortíz, al investigar las reacciones de los narcotraficantes ante las políticas de erradicación e interdicción aplicadas por el gobierno, encontrando que se ha generado un cambio tecnológico en las actividades ilegales que ha logrado compensar el impacto de las acciones de reprensión al mercado, lo cual ha permitido que los precios no suban, favoreciendo dicha actividad (Raffo, 2011, p. 300).

Ahora bien, también puede identificarse que entre los años 1991 y 2001, la segunda actividad fuente de ingresos de las FARC proviene de los secuestros y el valor de los rescates cobrados (Sánchez, 2013, p. 196). Cabe destacar que durante el proceso de negociación que se dio en ese tiempo, las conversaciones se fueron desgastando debido a que a que la guerrilla empezó a gobernar con gran ímpetu la zona de despeje, lo cual fue criticado por diversos actores, teniendo en cuenta que sus ataques militares nunca cesaron, y aunque se logró el intercambio de varios guerrilleros por soldados y policías, las FARC empezó a secuestrar políticos para presionar la liberación de un mayor número de sus compañeros. A esto se sumó el derrumbe de las torres gemelas, el 11 de septiembre de 2001, en el cual Estados Unidos declaró la guerra contra el terrorismo y destinó una gran cantidad de recursos financieros para apoyar el Plan Colombia.

Según cifras establecidas por el Centro Nacional de Memoria Histórica, las FARC realizó 8.644 secuestros entre los años 1991 y 2007, de los cuales 5.336 se realizaron entre 1998 y 2002 . Para el 2003 se calcula que los ingresos de las FARC por este concepto fue de 24.8 millones de dólares; así mismo se identifica la extorsión a empresas petroleras, hacendados, contratistas y administraciones municipales (Sánchez, 2013, p. 197). El incremento de secuestros se puede evidenciar en el siguiente gráfico: 
Análisis de la evolución histórica de la estructura económica de las Fuerzas Armadas Revolucionarias de Colombia (FARC) como factor principal de la perpetuación del conflicto armado colombiano

Gráfico No. 2. Secuestros de las guerrillas y el paramilitarismo entre 1991-2007.

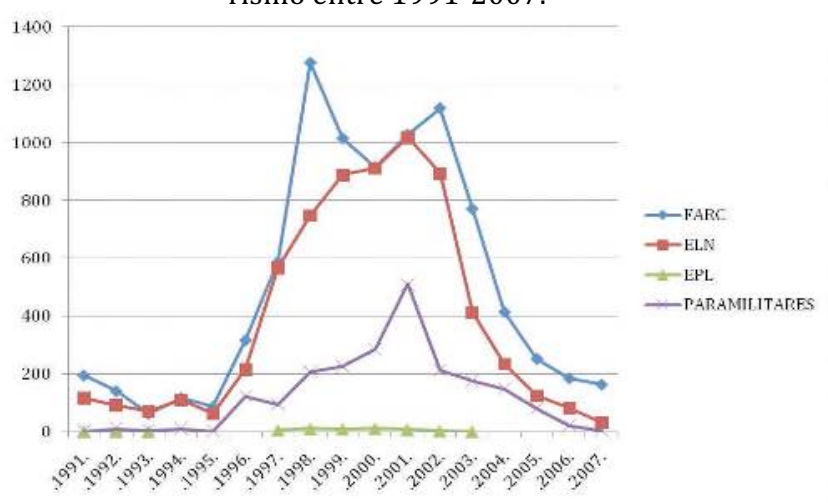

Fuente: Sánchez (2013), Guerrilla y Población Civil: Trayectoria de las FARC 1949-2013, Centro de Memoria Histórica, Bogotá- Colombia.

Teniendo en cuenta lo anterior, y al comparar el gráfico 1 y 2, se puede observar un incremento sustancial en los secuestros realizados en el año 1990; la causa principal es antecedida por las negociaciones del presidente Barco, quien hablando del surgimiento de una nueva constitución, logra la desmovilización del M-19; en consecuencia el presidente Gaviria continúa con las negociaciones ya iniciadas y logra hacer pactos con el Ejército Popular de Liberación, el Movimiento Armado Quitín Lame y el Partido Revolucionario de los trabajadores, garantizando una representativa participación en la Asamblea Nacional Constituyente. Sin embargo, teniendo en cuenta que las FARC habían decidido no negociar, el mismo día en que se iban a elegir a los constituyentes, se ordenó un ataque militar a la Casa Verde, conocida como la sede principal de este grupo guerrillero, con el fin de forzarlos a aceptar las condiciones del Gobierno para la reinserción a la vida civil, pero por el contrario la operación causó un endurecimiento por parte de las FARC y una posición más fuerte en cuanto a persistir en la guerra (Sánchez, 2013, p. 138), y por ende un incremento en las actividades de secuestro. Sin embargo en 1991 esta actividad disminuye y continúa con el promedio regular de secuestros, es decir menos de 100 por año, como puede observarse entre 1987 y 1995, a excepción del año 1990.

Por otra parte, podemos observar que para el año 2001 las FARC se habían convertido en un grupo armado auto sostenible y estructurado, que pese a algunas dificultades militares, había logrado mantenerse y resistir las acciones tomadas por el gobierno.

A partir del 2002, tras la puesta en marcha del Plan Patriota por parte del presidente Álvaro Uribe, las FARC empiezan a debilitarse. El conflicto aumentó y la fuerza pública continuaba fortaleciéndose, mientras que las FARC sufren el impacto de la muerte de varios de sus jefes y mandos medios, la liberación y fuga de secuestrados, la recuperación de territorios por parte del ejército y la mala administración del dinero producto del Narcotráfico. En consecuencia, la guerrilla intensificó sus prácticas de secuestro (como la pesca milagrosa), el uso de cilindros, campos minados, y la relación con el narcotráfico, causando así el rechazo por parte de: los medios de comunicación, actores internacionales como la Unión Europea quien la incluyó en la lista de organizaciones terroristas, e incluso de la población civil, que fue víctima de varios atentados. (Sánchez, 2013, p. 195), por lo que se le atribuyó el nombre de narcoterroristas.

Con el tiempo, el Plan Patriota empezó a evidenciar sus frutos, la guerrilla fue confinada en zonas selváticas y alejadas de varias ciudades, lo que causó problemas de salud y suministros en sus tropas; se desmovilizaron alrededor de 10.356 miembros (Cf. Gráfico 3), y se logró la captura y muerte de varios de sus cabecillas, entre ellos Raúl Reyes. En términos económicos también se vieron afectados, ya que se calcula que para el 2008 sólo contaban con presencia en el $50 \%$ de zonas cocaleras en relación al año 2002; así mismo los ingresos obtenidos en ese año, correspondientes a 1.300 millones de dólares, se redujeron a 500 millones en el 2007. (Sánchez, 2013, pp. 214-216).

Gráfico No. 3. Desmovilizados de las FARC 2003-2012

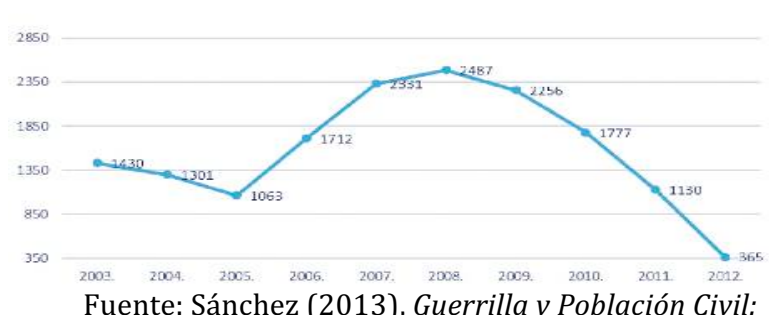

Fuente: Sánchez (2013), Guerrilla y Población Civil: Trayectoria de las FARC 1949-2013, Centro de Memoria Histórica (p. 85), Bogotá- Colombia.

Sin duda, la estructura económica de las FARC recibió un impacto por el número de desmovilizaciones y el abandono forzoso de algunas regiones cocaleras. Adicionalmente, otro factor relevante que incidió en su "deterioro" económico, coincidió con la relación entre el número de secuestros realizados hasta el año 2001 y los canjes conseguidos, ya que solo obtuvieron la libertad de 15 guerrilleros a cambio de 310 militares. Esperando mejores resultados, extendieron el cautiverio por años elevando así los costos de esta práctica y con el tiempo la mayoría murieron, otros fueron rescatados, y otros liberados sin ninguna ganancia; es así como además del incremento en costos militares y políticos, contribuyeron con el deterioro de su imagen como guerrilla revolucionaria (Castillo y Balbinotti, 2012, pp. 158-159). 


\section{Injerencia de la estructura económica de las FARC en la perpetuación del Conflicto}

Teniendo en cuenta el desarrollo económico de las FARC descrito anteriormente, con el fin de analizar su incidencia en la durabilidad del conflicto armado colombiano, es importante identificar las causas del origen de los conflictos internos de un Estado.

En primera instancia, se toma como punto de partida el postulado de Castaño (2013), quien define el conflicto como un aspecto inherente al ser humano, conllevándolo naturalmente a generar conductas violentas, de tal manera que la dinámica conflictiva no es autónoma ni separable de la dinámica cooperativa de los seres humanos. (p. 72). A su vez Grasa (2010), describe el conflicto como la "persecución de objetivos cuya consecución simultánea las personas o grupos consideran incompatibles de forma real o subjetiva" (Citado por Castaño, 2013:72). De allí que se conciba los conflictos de un Estado ingénitos a las relaciones humanas, en donde permanentemente existe una lucha por la consecución de intereses.

Por su parte Kaldor, denomina las guerras civiles 6 como "nuevas guerras", y argumenta que estas han aumentado, mientras que los conflictos interestatales han disminuido (p.17). Para Rovira (2005), "las nuevas guerras se han caracterizado por una lógica en donde el fin de conflicto no está previsto, sino que por el contrario se producen olas de menor y mayor violencia" (p. 184), En una misma línea, Münkler concuerda en que en las nuevas guerras poseen actores más allá del Estado - Nación, que tienen poderosos intereses económicos, lo que causa la prolongación de la guerra (Citado por Robira, 2005, p. 187).

Esto podría establecer el génesis del conflicto desde dos puntos de vista: uno que concibe las causas del conflicto interno de un Estado en las desigualdades socioeconómicas, la exclusión de ciertas regiones y la discriminación de ciertos actores de la población; y otra que atribuye a la codicia la motivación para fomentar la rebelión, tomando los incentivos financieros, producto de las rentas públicas y la explotación de recursos naturales, como instrumentos que juegan un papel fundamental en el inicio y desenvolvimiento de la violencia (Yaffe, 2011, p. 193).

En coherencia con lo anterior, se puede observar que las FARC se originaron con base en su insatisfacción frente a la desigualdad que existía respecto a la repartición de la tierra, y la poca retribución recibida por los campesinos, quienes eran los que realizaban el trabajo. Sin duda, esta lucha inició en busca de una reforma agraria que fuera más justa y que garantizara una mejor calidad de vida para el gremio.

Sin embargo, aunque las FARC inició una lucha en defensa de las clases sociales más excluidas, su incursión en actividades ilegales como el secuestro y el narcotráfico, que les dejaron cuantiosas ganancias, cambiaron su motivación inicial; prueba de esto son los recurrentes ataques en contra de la fuerza pública que con regularidad afectaron la población civil. Con el tiempo la presencia y dominio en lugares donde el Estado no se encontraba presente, fue una de las causas del rechazo hacia el grupo por parte de la población (Sánchez, 2013, p. 195).

$\mathrm{Al}$ respecto, se afirma que los resentimientos y las desigualdades económicas no son las raíces de los conflictos armados, sino los intereses económicos de algunos grupos en conflicto, teniendo en cuenta que en las regiones pobres se pueden conformar fuerzas armadas irregulares a muy bajos costos, que desafían la autoridad estatal con el fin de empoderarse de los recursos naturales saqueables (Bates, 2008, pp. 1-12). A su vez, se cuestiona la relación entre desigualdad y violencia, ya que esta relación desaparece cuando se controla el nivel de desarrollo económico. (Yaffe, 2011, pp. 193).

Adicionalmente, es notorio que en sus comienzos las FARC no obtenía la financiación suficiente para ser tenidos en cuenta como un grupo de acciones contundentes, de allí que en 1978 se socializara su plan denominado "nuevo modo de operar" en la VI Conferencia, que comprendía la expansión de sus tropas y su fortalecimiento bélico. Esta visión prospectiva fue la que impulsó a las FARC a participar en actividades ilícitas, de donde obtendrían los recursos necesarios para financiar el movimiento, y donde intencionalmente se ubicarían en zonas marginales, carentes de servicios públicos y con poco apoyo del Estado. De allí que investigaciones sobre la relación entre recursos explotables y conflictos armados, evidencian que las áreas ricas en recursos, se han convertido en puntos focales de confrontación, dada la importancia de controlar estas lucrativas zonas (Sánchez, 1998, pp. 37-58).

Al momento de abordar la categoría en la que se ve inmersa las FARC, luego de pasar por varias tan específicas como la denominación de guerrilla y otras tan difusas conceptualmente como la de narco-terrorista, algunos autores han catalogado a las FARC como una organización de crimen organizado pues cumple con varios criterios que se asemejan a estas de acuerdo a su desempeño, así pues, Martha Bottía establece que las FARC "1) tiene un orden claro y jerarquizado de tipo militar 2) desarrolla un negocio de tipo ilegal, cuya demanda es inelástica, el negocio de las drogas ilícitas; las actividades [de] secuestro, extorsión 3) crea sus propias reglas, limita el accionar de los agentes y preserva el control sobre determinadas áreas del territorio colombiano (algunos municipios en el Putumayo)". (Bottía, 2003, pág. 7)

\footnotetext{
6 También denominadas como conflictos internos.
} 
La evolución de la estructura económica, más allá de reflejar las condiciones sociales que dieron origen a las FARC o de representar las dinámicas propias de la confrontación armada de Colombia, dan muestra de la desviación de la ideología y de los principios fundacionales de la organización guerrillera. La ambición por el poder Estatal, consigna impregnada exógenamente por ideales revolucionarios marxistas y maoístas, así como el ejemplo de la victoria de la revolución cubana, no son más que sombras frente al devenir de las conductas que soportan sus finanzas. Un comportamiento plagado de vejámenes y atrocidades, violaciones a los Derechos Humanos y conductas delincuenciales e ilegales, que nublan el panorama al establecer que las causas de la perpetuación del conflicto son tan disímiles de las causas originarias, que la escalada de sucesos violentos que la guerrilla ha lanzado contra el pueblo deja en duda su ideario y la aceptación que tienen los colombianos de los autodenominados Ejército del Pueblo.

Así mismo y ratificando lo anterior, encontramos que dentro del debate de las causas del conflicto se encuentran otras concepciones, una que atribuye su origen a la falta de presencia del Estado y la provisión de bienes públicos en algunos sectores; y otra a la inclusión política, que al no ser suficiente puede generar grupos de oposición violenta. Goldstone, Gurr, Marshall y Vargas, (2004) muestran que el tipo de régimen político es determinante a la hora de generarse guerras y derrocamientos de regímenes. (Citado por Yaffe, 2011, p.194); este postulado es coherente con la dinámica del conflicto armado entre las FARC y el Estado colombiano en la medida en que, como se mencionó anteriormente, gran parte del auge bélico y económico de este grupo subversivo, se dio al lograr estructurarse como una organización "empresarial", que regularizó la producción y los precios de la cocaína, ejerciendo así control sobre la inflación, y optimizando las utilidades de esta actividad ilegal, y proveyendo recursos a los sectores rurales más precarios, que no contaban con presencia permanente e intervención del Estado.

Estos postulados ratifican las hipótesis de que los conflictos internos de un Estado son causados por las desigualdades sociales que incitan la naturaleza beligerante del ser humano, pero su perdurabilidad generalmente se asocia a las remuneraciones económicas atribuidas a quienes acceden a los recursos explotables y a actividades ilegales lucrativas, como se evidencia en el caso de las FARC y su relación con las zonas cocaleras.

El desarrollo de estas actividades ilícitas no solo conllevan a la perpetuación del conflicto, sino que favorecen, debido a su éxito demostrado, el surgimiento de organizaciones delincuenciales que intenten replicar el modelo, en una sociedad con altos índices de pobreza y pocas oportunidades en zonas donde los negocios ilegales como el secuestro, el narcotráfico, las extorsiones y otras atrocidades se muestran como la puerta de escape a una realidad que el mismo Estado no está en condiciones de cerrar.

\section{Conclusiones}

Las FARC se originaron con motivo de la insatisfacción frente a la desigualdad que existía respecto a la repartición de la tierra, y la poca retribución recibida por los campesinos; de allí surge la organización como un grupo de autodefensa en busca de una reforma agraria justa, que garantizara una repartición más equilibrada de los recursos y la recuperación económica de la clase obrera, en pro de una mejor calidad de vida para el gremio.

$\mathrm{Al}$ no tener muchos recursos para ser tenidos en cuenta como un grupo de acciones contundentes que influenciara las decisiones gubernamentales, en 1978 las FARC diseñó una estrategia bélica que le permitiera expandirse y ejercer presión, conduciéndolos poco a poco a la participación en actividades ilícitas, de donde obtendrían los recursos necesarios para financiar el movimiento e intencionalmente se ubicarían en zonas marginales, carentes de servicios públicos y con poco apoyo del Estado.

Estas zonas, caracterizadas por la producción de cocaína y marihuana, empezaron a ser controladas por diferentes frentes de las FARC, quienes además de participar de las ganancias de la extracción de recursos, brindaron apoyo social mediante la oferta de protección a los campesinos que se encontraban en manos de comerciantes y bandas criminales que se dedicaban al narcotráfico, la reducción de los niveles de violencia y la regulación de los precios de los estupefacientes. Así mismo las FARC incursionaron en otras actividades como el secuestro, la vacuna ganadera, los impuestos por producción de oro, las extorsiones a palmicultores y los asaltos.

De esta manera, para el año 2001 las FARC se habían consolidado como un grupo organizacionalmente estable, con recursos suficientes para auto sostenerse y financiar el desarrollo de actividades delictivas en las diferentes regiones del país. La adquisición de nuevas tecnologías, terrenos, pistas de aterrizaje, laboratorios de producción de cocaína y el fortalecimiento de relaciones con carteles de otros países, potencializó el narcotráfico en Colombia y así mismo garantizó el fortalecimiento del grupo.

Pese a su estabilidad económica, no se generó un impacto social benéfico tal como se esperaba con su conformación, los recurrentes ataques en contra de la fuerza pública afectaron la población civil, desvirtuando su intencionalidad de protección y 
defensa de los campesinos. Adicionalmente, el reclutamiento de menores, los enfrentamientos con paramilitares, el desplazamiento y el cobro regular de vacunas, causaron su desprestigio ante la comunidad.

Finalmente, la ejecución del Plan Colombia causó el debilitamiento de las FARC tanto organizacional como económicamente; a través de este proceso el gobierno logró la recuperación de territorios administrados por el grupo, la destrucción de laboratorios cocaleros y la muerte de cabecillas.

Es así como a través del análisis histórico del desarrollo de las FARC, podría establecerse que los conflictos internos de un Estado, en especial los originados en países en desarrollo, son causados por las desigualdades sociales que incitan la naturaleza beligerante del ser humano, pero su perdurabilidad generalmente se asocia a las remuneraciones económicas atribuidas a quienes acceden a los recursos explotables y a actividades ilegales lucrativas.

En otras palabras, este caso demuestra que la ausencia del Estado en sectores rurales, donde predomina la pobreza, facilita el surgimiento de conflictos internos y estructuras económicas ilegales, que con el tiempo son capaces de auto sostenerse e incluso, "suplantar" al Estado en la provisión de servicios y necesidades básicas.

Sin embargo, también se puede identificar que para estos grupos, la intencionalidad de incrementar la calidad de vida de la población más vulnerable, es viciada por los abundantes excedentes de las actividades ilícitas, dándole prioridad a los intereses económicos particulares por encima del bien común.
Ante estos sucesos, llegamos a esclarecer que las conductas económicas de las FARC han pasado por diferentes etapas, pasando de un comportamiento tradicional fisiócrata hasta llegar a ser considerado incluso un grupo característico del crimen organizado.

Las actuaciones ilícitas como el asocio con el narcotráfico, el cultivo y comercialización de estupefacientes, los atentados a instituciones bancarias destinadas al apoyo del sector agricultor colombiano, el secuestro y cobro de vacunas, se muestran en el escenario económico de esta organización como su principal sustento económico, factores principales para que más allá de un surgimiento por inconformidades sociales o por falta de presencia y apoyo estatal, el conflicto tenga la característica de perpetuación sustentado en estas actividades económicas, que han llevado a considerar al grupo subversivo como uno de los principales carteles de droga en el mundo, determinando dicha perpetuación del conflicto no en la lucha social y política que lo originó sino en un factor de codicia y captación de poder económico por medios ilegales bajo un control militar y territorial decidido. 
Análisis de la evolución histórica de la estructura económica de las Fuerzas Armadas Revolucionarias de Colombia (FARC) como factor principal de la perpetuación del conflicto armado colombiano

\section{Referencias}

Barón, M; \& Gutiérrez, F. (2008, Febrero). Ordenes Subsidiarios Coca, Esmeraldas: la guerra y la paz. Revista Colombia Internacional, No. 67, pp. 102-109.

Bates, R. (2008). State failure. Annual Review of Political Science 11(1), 1-12.

Bottía, M. (2003). La Presencia y Expansión Municipal de las FARC: Es avaricia y contagio, más que ausencia estatal. CEDE, pp. 1-56.

Bresser, L. (2009). El asalto al Estado y al mercado: neoliberalismo y teoría económica. Revista Nueva Sociedad, Núm. 221, pp. 85- 99.

Castaño, 0 (2013), Conflictos Armados y Construcción de Paz de la Teoría a las Políticas Internacionales de PAZ en la Posguerra Fría, Revista UAIM, Vol. 9, No. 2, ISSN-1665-0441, Julio- Diciembre.

Castillo, M. (2012). Las FARC y los costos del secuestro. Revista Economía Institucional, Vol. 14, pp. 147164.

Domínguez, M. (2004). El Papel de la Fisiocracia en nuestros días: una reflexión sobre el análisis económico de los recursos naturales y el medio ambiente. Revista Galega de Economía, Vol. 13 núm. 1-2, pp.112.

Ferrer, S (2003), La Formación de los Precios y la reproducción, Revista Política y Cultura No. 19, 2003, pp. 219-236, México.

Fisas, V (2004), Procesos de paz y negociación en conflictos armados. Barcelona: Paidos.

Franco, A. M., \& Ríos, I. d. (20111). Reforma Agraria en Colombia: evolución histórica del concepto. Hacia un enfoque integral actual. Cuaderno de Desarrollo Rural, p.p 93-119.

Gutiérrez y Barón (2008), Órdenes Subsidiarios, Coca, esmeraldas: la guerra la paz, Universidad de los Andes Revista Colombia Internacional 67 ene - jun 2008, ISSN 0121-5612, Bogotá, pp. 102 - 129

Olave, G (2013), El proceso de paz en Colombia según el Estado y las Farc-Ep, Revista Discurso \& Sociedad, Vol. 7(2), 2013, 338-363, Buenos Aires, Argentina.

Raffo L. (2011). “Narcotráfico y conflicto: ¿Por qué bajó el precio de la cocaína?”, Revista de Economía Institucional, Universidad del Externado de Colombia, Vol. 12, No 23, pp. 229-258.

Rovira, C (2005), Nuevas y Viejas Guerras: asimetría y prvatización de la Violencia, Herfried Munclker, Siglo XXI Editores, Madrid

Salazar, G (2005), Mirada Crítica al Conflicto Colombiano Armado Colombiano, Memorias del Seminariotaller Internacional de contextualización sobre desplazamiento forzado y refugio en zonas de frontera, Bogotá, ACNUR

Sánchez, G (2013), Guerrilla y Población Civil: Trayectoria de las FARC 1949-2013, Centro de Memoria Histórica, IBN 978-958-58167-02, Imprenta Nacional de Colombia, Bogotá- Colombia.

Yaffe, Lilian (2011) Conflicto armado en Colombia: análisis de las causas económicas, sociales e institucionales de la oposición violenta, Revista CS, ISSN 2011- 0324 No. 8, pp. 187 - 208, julio - diciembre 2011. Cali - Colombia.

Valencia, G. (2006, Diciembre). La economía frente al conflicto armado interno colombiano, 1990-2006. Perfil de coyuntura económica, Núm. 8, pp. 141-174. 